\title{
Enhancement of Antimicrobial and Antiproliferative Activities of Standardized Frankincense Extract Using Optimized Self-Nanoemulsifying Delivery System
}

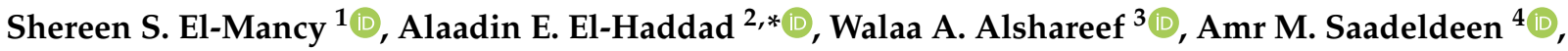 \\ Soad Z. El-Emam ${ }^{5}$ and Osama S. Elnahas ${ }^{1}$ \\ 1 Department of Pharmaceutics and Industrial Pharmacy, Faculty of Pharmacy, October 6 University, \\ Giza 12585, Egypt; shereenelmancy@o6u.edu.eg (S.S.E.-M.); osamaelnahas@o6u.edu.eg (O.S.E.) \\ 2 Department of Pharmacognosy, Faculty of Pharmacy, October 6 University, Giza 12585, Egypt \\ 3 Department of Microbiology and Immunology, Faculty of Pharmacy, October 6 University, Giza 12585, Egypt; \\ dr.walaa@o6u.edu.eg \\ 4 Department of Pharmacognosy, School of Pharmacy, Newgiza University, Giza 12556, Egypt; \\ amr.saadeldeen@ngu.edu.eg \\ 5 Department of Pharmacology and Toxicology, Faculty of Pharmacy, October 6 University, Giza 12585, Egypt; \\ soadzakaria@o6u.edu.eg \\ * Correspondence: alaa_elhaddad.ph@o6u.edu.eg or Haddad002@yahoo.com; Fax: +20-238354275
}

Citation: El-Mancy, S.S.; El-Haddad, A.E.; Alshareef, W.A.; Saadeldeen, A.M.; El-Emam, S.Z.; Elnahas, O.S. Enhancement of Antimicrobial and Antiproliferative Activities of Standardized Frankincense Extract Using Optimized Self-Nanoemulsifying Delivery System. Sci. Pharm. 2021, 89, 36. https://doi.org/10.3390/ scipharm89030036

Academic Editor: Bruno Sarmento

Received: 3 June 2021

Accepted: 28 July 2021

Published: 2 August 2021

Publisher's Note: MDPI stays neutral with regard to jurisdictional claims in published maps and institutional affiliations.

Copyright: (c) 2021 by the authors. Licensee MDPI, Basel, Switzerland. This article is an open access article distributed under the terms and conditions of the Creative Commons Attribution (CC BY) license (https:/ / creativecommons.org/licenses/by/ $4.0 /)$.
Abstract: Boswellic acids (BAs) are the main bioactive compounds of frankincense, a natural resin obtained from the genus Boswellia. This study aimed to develop a self-nanoemulsifying delivery system (SNEDS) to improve the antimicrobial and antiproliferative activities of standardized frankincense extract (Fr-extract). Fr-extract was standardized, and BA content was quantified using the developed HPLC-UV method. Screening studies of excipients followed by formula optimization using a mixture simplex lattice design was employed. The optimized Fr-SENDS formulation was characterized. Furthermore, microbiological and antiproliferative assessments of the standardized Fr-extract and Fr-SNEDS were evaluated. Quantification demonstrated that the major constituent is 11-keto-boswellic acid (KBA) (16.25\%) among BA content (44.96\%). The optimized Fr-SENDS (composed of $5 \%$ Capryol $^{\text {TM }} 90,48.7 \%$ Gelucire ${ }^{\circledR} 44 / 14$ and $46.3 \%$ ethanol) showed spherical nanosized dispersions with DS, PDI, and zeta potential of $17.9 \mathrm{~nm}, 0.2$, and $-14.5 \mathrm{mV}$, respectively. Fr-SNEDS exhibited lower MIC and MBC values compared with Fr-extract against pathogens conjugated with lung cancer and was comparable to reference antimicrobials. Fr-SNEDS showed superior antiproliferative activity over Fr-extract, with $\mathrm{IC}_{50}$ values of 20.49 and $109.5 \mu \mathrm{g} \mathrm{mL}{ }^{-1}$, respectively. In conclusion, the optimized Fr-SNEDS could be easily developed and manufactured at a low cost and the in vitro results support its use as a potential adjuvant oral therapy for lung cancer. Further in vivo studies could be continued to assess the therapeutic efficiency of the prepared system.

Keywords: antiproliferative; boswellic acids; frankincense; MRSA; self-nanoemulsifying delivery system; simplex lattice design

\section{Introduction}

Nowadays, researchers are moving towards the utilization of phytoconstituents, owing to their therapeutic effectiveness with low side effects [1]. Frankincense, or olibanum, is a natural resin obtained from trees of the genus Boswellia, which is widespread in Arabia and India. Frankincense is comprised mainly of oleogum and terpenoids. Frankincense pentacyclic triterpenes are considered to be the most bioactive. Among triterpenoids, boswellic acids (BAs) are of particular interest, particularly $\beta$-boswellic acid and 11-Keto- $\beta$ boswellic acid (KBA) and their 3-O-acetyl esters (AKBAs) [1]. The major composition of the Boswellia resin shows approximately $50-60 \%$ of various BAs, and in herbal supplements, up to $65 \%$ [2]. The analysis of these triterpenes is performed by different analytical methods 
based on HPLC-DAD [3] and LC/MS [1,4]. A novel chromatographic separation method for selective analysis of the $\alpha$ - and $\beta$-isomers of KBA and AKBA showed that $\alpha$-KBA produces only a small proportion (1.1-7.8\%) of the total KBAs in oleogum resins of $B$. sacra. Similarly, $\alpha$-AKBA produces only $0.5-6.4 \%$ of the total AKBAs and the majors were $\beta$-isomers [5]. AKBA possesses antibacterial activity against Gram-positive bacteria and inhibits the biofilm generated by Staphylococcus [6]. On other hand, Boswellia triterpenoids were reported to have antitumor properties [7], apoptotic effects, and inhibited the protein synthesis in human leukemia cells [8]. Moreover, both $\alpha$ - and $\beta$-KBA exhibited cytotoxicity against triple-negative breast cancer (TNBC) cell lines and induced in vivo apoptosis in MDA-MB-231 xenografts, where the $\beta$-isomers of KBA and AKBA demonstrated higher cytotoxic efficacies [5]. Furthermore, AKBA has an inhibitory effect on lipoxygenases following inhibition of cell proliferation [9].

AKBA is a class IV drug according to bio classification system (BCS) [10], and it is a challenge to improve its solubility and permeability. The development of nanocarriers offers many advantages, such as improving solubility, bioavailability, and stability, which consequently increases the therapeutic activity of drugs [11]. There are several studies that illustrated the use of nano-preparations as potential drug delivery systems for phytoconstituents [12-14]. Over recent years, the utilization of self-nanoemulsifying delivery systems (SNEDS) has been of great interest. After oral administration of SNEDS, and upon contact with GIT fluids, they produce nanoemulsions (droplet sizes 20-200 nm), which allow a large interfacial surface area for drug absorption, resulting in an enhanced oral bioavailability of poorly water-soluble drugs [15-17]. SNEDS have been used for developing drug delivery systems of some phytoconstituents such as curcumin [18], cinnamon oil [19], morin [13], curcumin, and thymoquinone [20]. Several studies have showed that SNEDS improved the anticancer activity of drugs $[21,22]$ and of phytoconstituents $[23,24]$. Self-emulsification depends on the characters of oils, surfactants, and cosurfactants, their ratios, and the temperature during emulsification procedure. Moreover, efficient self-emulsifying systems need very specific combinations of pharmaceutical excipients $[15,25,26]$. Pharmaceutical optimization of SNEDS is often based on the construction of phase diagrams, which is time-consuming. Design of experiment (DoE) has been used for formulation development and optimization to save time and effort, where application of a suitable design allows screening of different variables simultaneously. The systematic optimization technique includes measuring the response variables, fitting a mathematical model, and conducting appropriate statistical tests to ensure the optimum formulation composition $[25,27]$.

Herbal medicines were not considered for the development of novel dosage forms due to formulation difficulties. Modern formulation can be utilized to enhance phytoconstituents efficacy [28]. In this study, we present a rationale for the development of SNEDS as a suitable oral form of Fr-extract. BAs were quantified in Fr-extract; subsequently, Fr-SNEDS were prepared using DoE for formulation optimization. Finally, the optimized Fr-SNEDS formulation was subjected to antimicrobial and antiproliferative studies compared with Fr-extract.

\section{Material and Methods}

\subsection{Materials}

\subsubsection{Chemicals}

Boswellia sacra Flueck. gum oleoresin was purchased from Harraz Egyptian herbal store, Cairo, Egypt. KBA, AKBA, doxorubicin-hydrochloride ( $\geq 98.0 \%)$, MTT, propidium iodide, DMSO, Tween 80, isopropyl myristate (IPM), Kolliphor ${ }^{\circledR}$ RH40, and propylene glycol (PG) were purchased from Merck, Darmstadt, Germany. Dent (Oxoid Helicobacter pylori) selective supplement, nitrofurantoin, amoxacillin/clavulanic acid, cefepime, metronidazole, and fluconazole discs were purchased from HiMedia Laboratories, Mumbai, India. Capryol $^{\mathrm{TM}}$ 90, Labrafil ${ }^{\circledR}$ M 1944 CS, Gelucire ${ }^{\circledR} 44 / 14$, Labrasol ${ }^{\circledR}$ were a kind gift from 
Gattefosse, Saint-Priest, France. Polyethylene glycol 400 (PEG400) was purchased from Fluka, Buchs, Switzerland. All other chemicals were of analytical reagent grade.

\subsubsection{Microbial Strains and Cell Lines}

Gram-positive microbial strains Bacillus subttilis (ATCC 6633), Micrococcus luteus (ATCC 27566), Staphylococcus aureus (ATCC 25923), Staphylococcus epidermidis (ATCC 12228), and MRSA (ATCC 43300), along with Gram-negative strain Helicobacter pylori (ATCC 43504) and yeast strain Candida albicans (ATCC 10231) were used to evaluate the antimicrobial potency. The microbial strains and cell line (A549) were provided by the Microbiology and Immunology Department and the Cell Culture Unit, respectively, at the Faculty of Pharmacy, October 6 University, Giza, Egypt.

\subsection{Methods}

\subsubsection{Plant Extraction}

Frankincense extract (Fr-extract) was prepared from gum oleoresin $(1 \mathrm{Kg})$ with ethanol $(70 \%)$ via Soxhlet extraction. The solvent was filtered and evaporated $\left(40-50{ }^{\circ} \mathrm{C}\right)$ until dryness (Rotavapor ${ }^{\circledR}$ R-300, BÜCHI, Switzerland) [29]. Fr-extract was subjected to HPLC quantification, SNEDS formulation, and in vitro biological studies.

\subsubsection{HPLC Standardization}

Based on pentacyclic boswellic acids, HPLC standardization of BAs was performed on Shimadzu (LC-20AT series) equipped with multiple wavelength detector (SPD-20 AD) and prontosil ODS $\mathrm{C}_{18}$ column $(5 \mu \mathrm{m}, 15 \mathrm{~cm} \times 4.5 \mathrm{~mm})$. Quantification was performed using an isocratic elution with acetonitrile:water:acetic acid (99:1:0.01 v/v/v) with $1 \mathrm{~mL} \mathrm{~min}^{-1}$ flow rate [2]. Ultraviolet monitoring was carried out at 210 and $260 \mathrm{~nm}$, and the retention times $\left(R_{t}\right)$ were determined [30]. The validation method was conducted according to ICH guidelines [31].

\subsection{Formulation Development and Optimization of Fr-SNEDS}

\subsubsection{Screening of Different Excipients for Development of Fr-SNEDS}

A solubility study was performed to select the most suitable excipients for SNEDS formulation. The solubility of the standardized Fr-extract in various oils (Labrafil ${ }^{\circledR}$ M 1944, Capryol $90^{\mathrm{TM}}$, Myritol 318, and IPM), in 10\% solutions of different surfactants (Labrasol ${ }^{\circledR}$, Gelucire $^{\circledR} 44 / 14$, Kolliphor ${ }^{\circledR}$ RH40, and Tween 80), and in different cosurfactants (PG, PEG400, and ethanol) was investigated. An accurate weight of Fr-extract (0.2 g) was mixed with each excipient $(1 \mathrm{~mL})$ and stirred using a vortex mixer $(10 \mathrm{~min})$, and the mixtures were shaken in screw-cap glass vials $\left(24 \mathrm{~h}, 25 \pm 2{ }^{\circ} \mathrm{C}\right)$. The formed mixtures were visually inspected and classified as completely soluble, slightly soluble, or insoluble. The suitable oil was selected based on the solubility study. To select the appropriate surfactant and cosurfactant, besides the solubility study results, the ability of the surfactant and the cosurfactant to emulsify the selected oil was screened. Briefly, oil and surfactant were mixed $(1: 1 \mathrm{w} / \mathrm{w})$, then water was added dropwise with stirring until the first turbidity. The maximum amount of water incorporated into the mixture served as the standard in the final selection of the surfactant. The cosurfactants were similarly screened with the selected surfactant [32]. Water incorporation \% was calculated by the following equation:

Water incorporation $(\%)=[($ weight of water added $) /($ weight of mixture + weight of water added $)] \times 100$

\subsubsection{Experimental Design for Development and Optimization of Fr-SNEDS}

The used oil, surfactant, and cosurfactant were selected based on the screening study. DoE was conducted for the development and statistical optimization of Fr-SNEDS formulation. A mixture simplex lattice design was employed using the Design-Expert software (Version 11.1.2.0; Stat-Ease Inc., USA). The independent variables were represented by the mixture's three components (oil (A), surfactant (B), and cosurfactant (C)). The low and high 
values for each component were designated as (0.05 to 0.9). According to the proceeded simplex design, 13 formulations were prepared. Figure 1 shows the schematic presentation of the experimental domain in the ternary diagram, and the conducted experimental points. Droplet size (DS) (Y1) and polydispersity index (PDI) (Y2) were set as dependent variables. Analysis of variance (ANOVA) was carried out to estimate the significance $(p<0.05)$ of each factor. The best fitting mathematical model was selected based on the comparison of several statistical parameters, namely the multiple correlation coefficient $\left(R^{2}\right)$ and adjusted $R^{2}$. The factor effect plots and response surface plots were generated using the same software. For each formulation, an appropriate amount of the Fr-extract to prepare Fr-SNEDS (2\%) was dissolved in the specified composition of the oil, surfactant, and cosurfactant by stirring (15 min) until completely dissolved and then stored in closed containers before further evaluation. Each formulation was diluted 100 times by mixing with double distilled water and the mean DS and PDI of the formed dispersion were determined by dynamic light scattering (DLS) technique using a Zetasizer (ZS, Malvern, UK) at $\left(25 \pm 2{ }^{\circ} \mathrm{C}\right)$. A laser beam (at $632 \mathrm{~nm}$ ) was applied, and the light scattering was monitored at a fixed angle of $173^{\circ}$ and the run time was selected to be automatic to adopt best reading of the sample. The DS was expressed as Z-average (d. $\mathrm{nm}$ ), which represents the grand average of all the intensities that the DLS picks up. The optimized formulation was determined by the software using the desirability function to attain minimum DS and PDI.

\section{(A)}

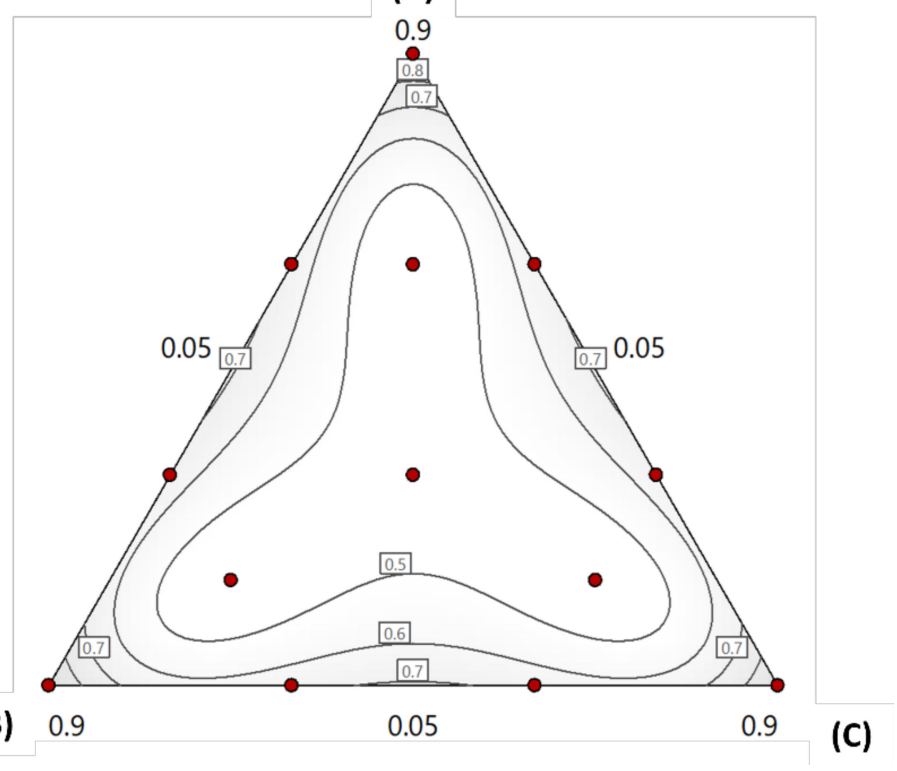

Figure 1. Simplex lattice design used for optimization of Fr-SNEDS (oil (A), surfactant (B), and cosurfactant (C)).

\subsection{Characterization of the Optimized Fr-SNEDS}

2.4.1. Visual Inspection, DS, PDI, and Zeta Potential (ZP) Measurements

The optimized Fr-SNEDS was inspected visually against strong light for optical transparency and homogeneity. DS and PDI were determined as previously mentioned, and ZP was measured. Measurements were performed in triplicates at $25^{\circ} \mathrm{C}$.

\subsubsection{Assessment of Self-Emulsification Efficiency}

The rate of emulsification is an important index for the assessment of the efficacy of SNEDS. The test was performed using a USP II dissolution apparatus (Distek 2500, North Brunswick Township, NJ, USA). A watch glass containing formulation (0.5 g) was introduced into $\mathrm{HCl}(0.1 \mathrm{~N}, \mathrm{pH} 1.2,500 \mathrm{~mL})$ at $37 \pm 0.5^{\circ} \mathrm{C}$ with gentle agitation $(100 \mathrm{rpm})$. The performance of self-emulsification was assessed visually by monitoring the time 
required for the complete disappearance of the formulation and formation of a clear dispersion $[33,34]$. The formed dispersion was evaluated by measuring the percent transmittance using a UV-vis spectrophotometer at $638 \mathrm{~nm}$ (UV-160A, Shimadzu, Japan) against double distilled water as the blank [35]. All determinations were performed in triplicates.

\subsubsection{Thermodynamic Stability}

The optimized Fr-SNEDS was subjected to 2 stress tests to assess its stability and ability to withstand thermal changes. The optimized Fr-SNEDS was subjected to centrifugation test (3000 rpm, $30 \mathrm{~min}$ ) and freezing-thawing cycles ( 3 complete cycles, each of $24 \mathrm{~h}$ at $-5{ }^{\circ} \mathrm{C}$, followed by $24 \mathrm{~h}$ at $25{ }^{\circ} \mathrm{C}$ ). At the end of each test, the formulation was examined visually for phase separation or extract precipitation.

\subsubsection{Study of Surface Morphology by Transmission Electron Microscopy (TEM)}

The morphology of the optimized Fr-SNEDS was investigated by 200 kV Field Emission (FE) TEM (JEM-2100, JEOL Ltd., Tokyo, Japan) integrated in PC control system enables scanning images of a sample at nanometer resolution. A drop of a diluted aqueous dispersion of the formulation was dropped onto copper-coated carbon grids, dried, then stained with phosphotungstic acid $(2 \% w / v)$.

\subsection{Assessment of Antimicrobial Activity}

2.5.1. Preparation of the Inoculum

Microbial biofilm strains B. subtilis, M. luteus, S. aureus, S. epidermidis, and MRSA were sub-cultured aerobically overnight $\left(35^{\circ} \mathrm{C}\right)$ in Mueller-Hilton agar. C. albicans and $\mathrm{H}$. pylori were inoculated in sabouraud agar $\left(48 \mathrm{~h}, 25^{\circ} \mathrm{C}\right)$, and microaerophilic $\left(5 \% \mathrm{CO}_{2}, 72 \mathrm{~h}, 37^{\circ} \mathrm{C}\right)$ in supplemented Columbia blood agar. The microbial growth was diluted to attain 0.5 MacFarland turbidity standard using a spectrophotometer $(590 \mathrm{~nm})$.

\subsubsection{Sensitivity Test}

The antimicrobial susceptibility of the microbial biofilm strains were determined against antimicrobial agents (positive control), Fr-extract, and Fr-SNEDS using Kirby Bauer disk diffusion [36,37]. Fr-extract (10 $\mathrm{mg} \mathrm{mL}^{-1}$ in DMSO), Fr-SNEDS dispersion in sterile water (equivalent to $10 \mathrm{mg} \mathrm{mL}^{-1}$ Fr-extract), and plain SNEDS dispersion were sterilized through a millipore filter $(0.22 \mathrm{~mm})$, then loaded over sterile discs $(6 \mathrm{~mm})$ on supplemented petri dishes with respective strains in a concentration of $0.5 \mathrm{MacFarland}$ standard. The plates were incubated as respective conditions and the zones of inhibition $(\mathrm{mm})$ were measured in triplicates.

\subsubsection{Minimum Inhibitory Concentrations (MICs) and Minimum Biocidal Concentrations (MBC)}

The lowest concentration that inhibits the microbial growth (MIC) and the lowest concentration required to kill a microbe over a fixed period (18 or $24 \mathrm{~h}$ ) (MBC) for Fr-extract and Fr-SNEDS were determined using broth microdilution method [37]. Separately, serial dilutions of samples (200 to $5 \mu \mathrm{g} \mathrm{mL}^{-1}$ ) were inoculated with respective microbes $(10 \mu \mathrm{L})$, evaluated, and microbial counts $\left(\mathrm{CFU} \mathrm{mL}{ }^{-1}\right)$ were determined in triplicates using an ELISA plate reader (Infinite F50 Tecan-Sweden, $620 \mathrm{~nm}$ ) [38].

\subsection{In Vitro Antiproliferative Assay}

Antiproliferative assay (as $\mathrm{IC}_{50}$ ) of the standardized Fr-extract and Fr-SNEDS were performed using the MTT assay [39]. Briefly, A549 cells $\left(1 \times 10^{3}\right.$ cells $\left.\mathrm{mL}^{-1}\right)$ were plated in 96-well plates and allowed to attach for $24 \mathrm{~h}$, resulting in a log phase growth at the time of drug treatment. Serial dilutions $\left(100-1.56 \mu \mathrm{g} \mathrm{mL}^{-1}\right)$ of the Fr-extract in DMSO, Fr-SNEDS, and plain SNEDS dispersions in distilled water were added to the cells. Cells were also treated with each component of the plain SNEDS formulation individually in the same concentration range used in the formulation. After treatment, MTT $(10 \mu \mathrm{L})$ was added to 
each well, incubated $\left(4 \mathrm{~h}\right.$, at $\left.37^{\circ} \mathrm{C}\right)$, and the produced formazan was solubilized in DMSO $(100 \mu \mathrm{L})$. The absorbance was measured using a microplate ELISA reader (FLUOstar Omega, BMG, Labtech, Germany) at $490 \mathrm{~nm}$. The percentage of relative cell viability was calculated using the following equation: Cell viability $\%=$ [Absorbance of treated cells / Absorbance of control cells)] $\times 100$.

Each concentration was performed in triplicates and the data were analyzed using GraphPad Prism 6 (La Jolla, CA, USA). The values of cell viability \% versus a series of sample concentrations were then plotted using non-linear regression analysis of Sigmoidal dose-response curve generated with the equation $\mathrm{Y}=\mathrm{B}+(\mathrm{T}-\mathrm{B}) / 1+10((\log \mathrm{EC} 50-\mathrm{X}) \times$ Hill Slope), where $\mathrm{Y}=$ percent cell, $\mathrm{B}=$ minimum percent cell, $\mathrm{T}=$ maximum percent cell, $X=$ logarithm of compound, and Hill Slope = slope factor or Hill coefficient [29].

\subsection{Stability Study}

The optimized Fr-SNEDS was stored in a dark place for 12 months at $25 \pm 2{ }^{\circ} \mathrm{C}$ and $65 \%$ relative humidity. The effect of storage on clarity, DS, PDI, ZP, surface morphology, and self-emulsification efficiency was evaluated.

\section{Results}

\subsection{Standardization of BAs in fr-Extract}

The quantification of bioactive BAs is essential for their use in dietary supplements. BAs, a mixture comprised of four major triterpenes, namely $\beta$-boswellic acid ( $\beta$-BA), 3acetyl- $\beta$-BA, 11-keto-boswellic acid (KBA), and 3-acetyl-11-keto-boswellic acid (AKBA), and two minors, namely $\alpha$-boswellic acid ( $\alpha$-BA), and 3-acetyl- $\alpha$-BA, were isolated from the oleogum resin of Boswellia species [1]. KBA and AKBA are considered the most active BAs. It is noteworthy that the $R_{t}$ of KBA and $\beta$-BA in the performed HPLC analysis are 2.5 and $6.5 \mathrm{~min}$, respectively (Table 1), in agreement with those reported (2.6-3.4 and 7.5-8.6 min, respectively) [2]. However, their acetyl derivatives $R_{t}$ were 3.7 and $7.9 \mathrm{~min}$, respectively (Figure 2), also in agreement with those reported (3.5-4.2 and 11.5-12.2 $\mathrm{min}$, respectively) [2].

Table 1. HPLC determination of BAs in frankincense extract.

\begin{tabular}{ccc}
\hline Compound & $\boldsymbol{R}_{\boldsymbol{t}}(\mathbf{m i n})$ & Content $\%$ \\
\hline 11-keto-boswellic acid & 2.5 & $16.25 \%$ (major) \\
Acetyl-11-keto-boswellic acid & 3.7 & $11.8 \%$ (major) \\
$\alpha$-boswellic acid & 5.8 & $2.19 \%$ (minor) \\
$\beta$-boswellic acid & 6.5 & $8.76 \%$ (major) \\
Acetyl- $\alpha$-boswellic acid & 7.5 & $2.5 \%$ (minor) \\
Acetyl- $\beta$-boswellic acid & 7.9 & $3.46 \%$ (minor) \\
\hline & Total content & $44.96 \%$ \\
\hline
\end{tabular}

\subsection{Formulation Development and Optimization of Fr-SNEDS}

\subsubsection{Screening of Excipients}

We investigated the ability of the excipients to dissolve a known fixed amount of the Fr-extract (10 times the loaded drug amount) in the tested excipients. Among the tested oils, only Capryol ${ }^{\mathrm{TM}} 90$ showed a good Fr-extract solubility (Table 2). After the selection of the oil phase, the goal was to identify the surfactant and cosurfactant that have both good Fr-extract solubility and emulsification ability of Capryol ${ }^{\text {TM }}$ 90. Gelucire ${ }^{\circledR}$ 44/14, PG, PEG400, and ethanol showed good Fr-extract solubility (Table 2). However, the main selection perspective for the surfactant and cosurfactant was the emulsification ability of the selected oil rather than Fr-extract solubility. Gelucire ${ }^{\circledR} 44 / 14$ had a superior ability to emulsify Capryol ${ }^{\mathrm{TM}} 90$, followed by Tween 80 and Labrasol ${ }^{\circledR}$, whereas Kolliphor $^{\circledR}$ RH40 showed the lowest emulsification ability for the oil based on the water incorporation percent (Figure 3). The selection of cosurfactant was also based on emulsification ability, 
where ethanol showed the highest water incorporation \% when combined with Gelucire ${ }^{\circledR}$ $44 / 14$ as a surfactant. Finally, Capryol ${ }^{\mathrm{TM}} 90$ was selected as the oil phase because it showed a good Fr-extract solubility, and Gelucire ${ }^{\circledR} 44 / 14$ and ethanol were selected as surfactant and cosurfactant as they recorded good Fr-extract solubility and good Capryol ${ }^{\mathrm{TM}}$ 90 emulsification ability.
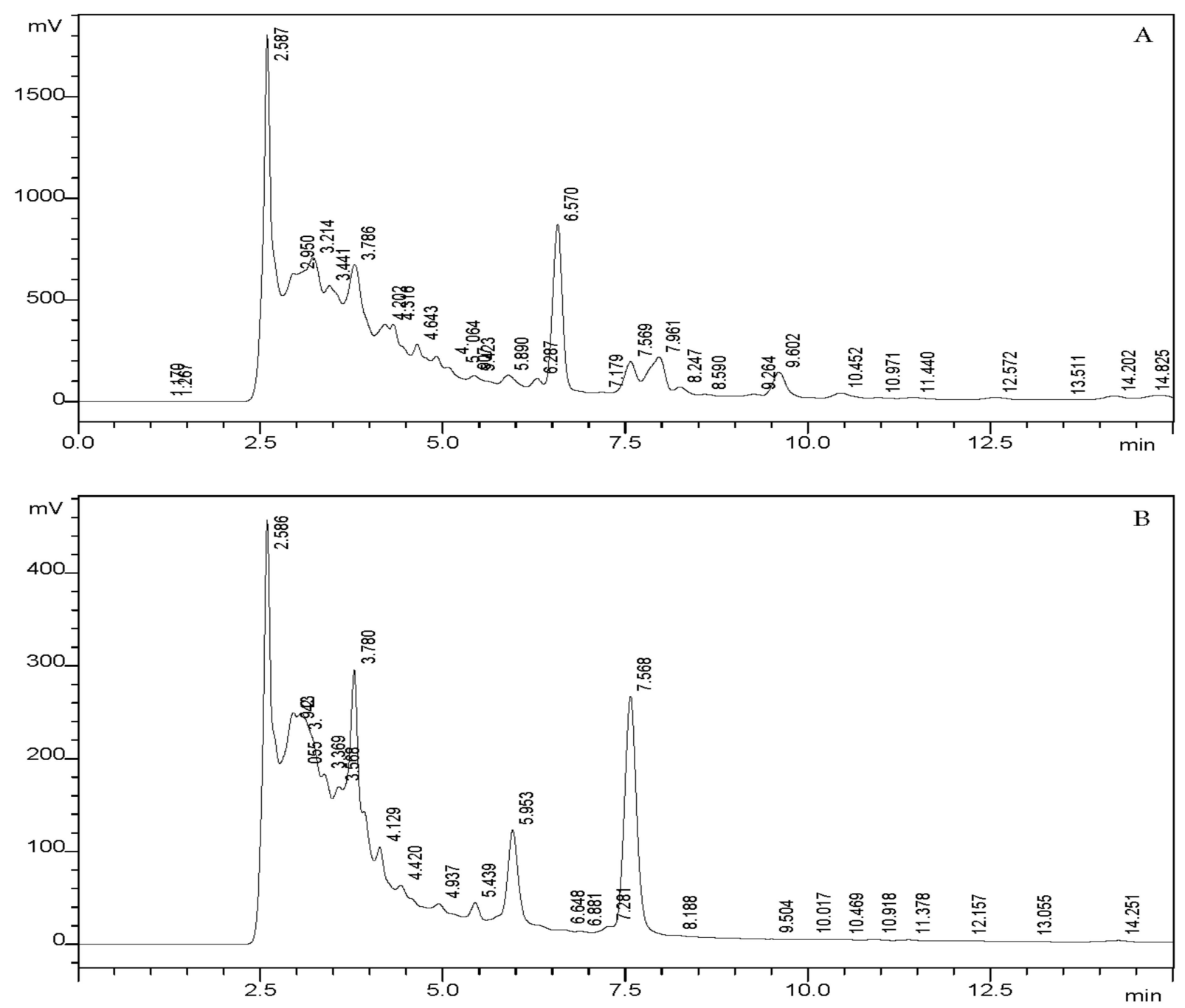

Figure 2. Analytical HPLC-UV chromatograms of frankincense extract at (A) $210 \mathrm{~nm}$ and (B) $260 \mathrm{~nm}$.

Table 2. Solubility study observations of frankincense extract in different oils, surfactants (10\% solutions), and cosurfactants.

\begin{tabular}{cc}
\hline Excipient & Observed Solubility \\
\hline Labrafil $^{\circledR}$ M 1944 CS & Slightly soluble \\
Capryol $^{\text {TM } 90}$ & Completely soluble \\
IPM & Insoluble \\
Myritol 318 & Insoluble \\
Tween 80 & Slightly soluble \\
Gelucire $^{\circledR} 44 / 14$ & Completely soluble \\
Labrasol $^{\circledR}$ & Slightly soluble \\
Kolliphor $^{\circledR}$ RH40 & Insoluble \\
PG & Completely soluble \\
PEG400 & Completely soluble \\
Ethanol & Completely soluble \\
\hline
\end{tabular}




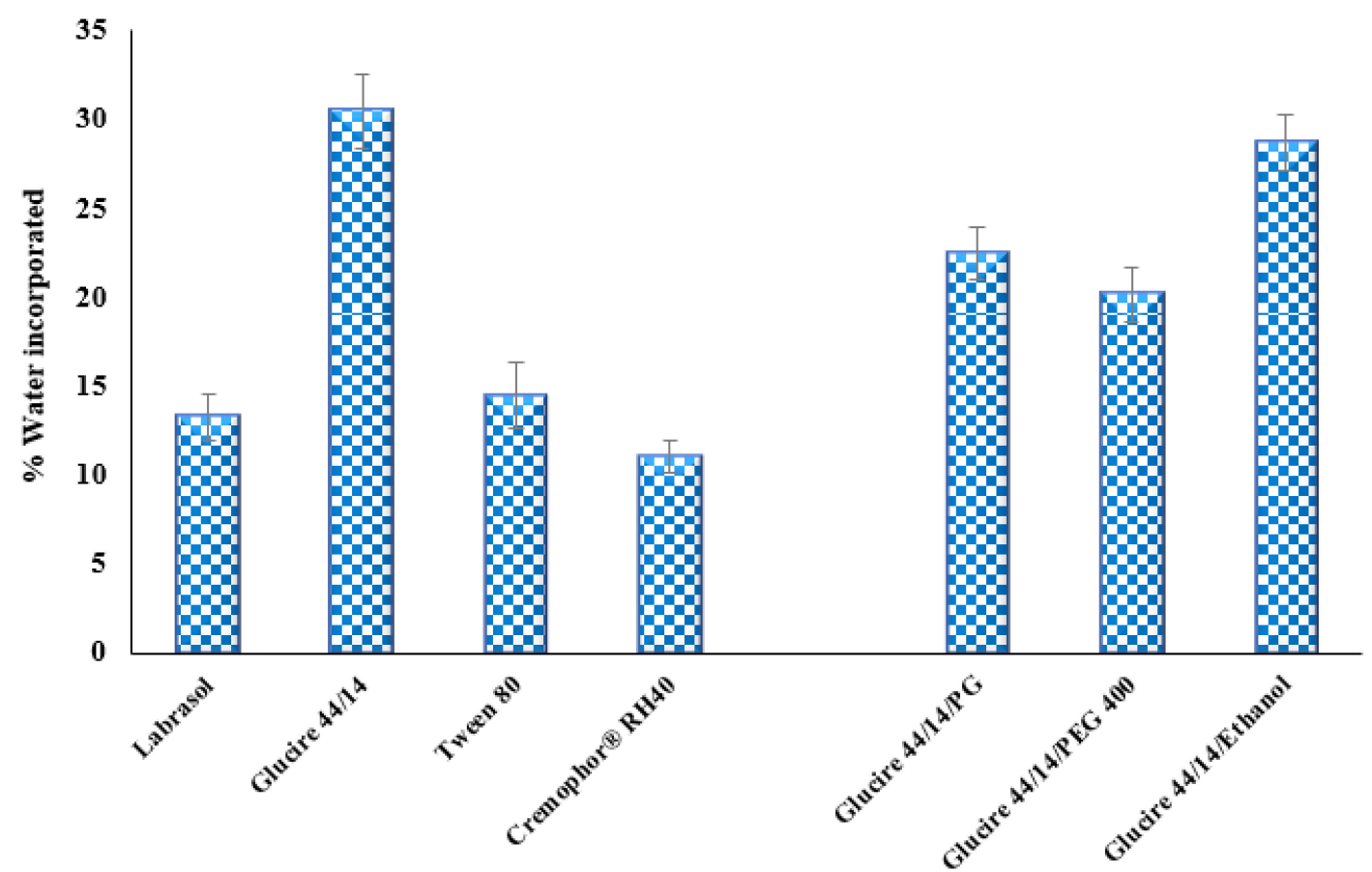

Figure 3. Percentage of water incorporated into mixtures of Capryol ${ }^{\mathrm{TM}} 90$ and different surfactants and surfactant/cosurfactant mixtures (mean $\pm \mathrm{SD}, n=3$ ).

\subsubsection{Experimental Design}

Based on the screening study, Capryol ${ }^{\mathrm{TM}} 90$, Gelucire ${ }^{\circledR} 44 / 14$, and ethanol were used for Fr-SNEDS formulation. A simplex lattice design was used to investigate the effect of the independent variables (oil $\left(\mathrm{X}_{1}\right)$, surfactant $\left(\mathrm{X}_{2}\right)$, and cosurfactant $\left(\mathrm{X}_{3}\right)$ concentrations) on the dependent variables (DS (Y1) and PDI (Y2)). The experimental matrix for the prepared 13 Fr-SNEDS formulations and the corresponding responses of DS and PDI is presented in Table 3.

Table 3. Experimental runs suggested by simplex lattice mixture design approach for the optimization of Fr-SNEDS and the determined responses. Data are expressed as mean $\pm \mathrm{SD}(n=3)$.

\begin{tabular}{cccccc}
\hline & \multicolumn{2}{c}{ Factors } & \multicolumn{2}{c}{ Responses } \\
\hline * Formulation No. & Oil (A) Capryol ${ }^{\text {TM }} \mathbf{9 0}$ & $\begin{array}{c}\text { Surfactant (B) } \\
\text { Gelucire }^{\circledR} \text { 44/14 }\end{array}$ & CoS (C) Ethanol & DS (nm) & PDI \\
\hline 1 & 0.19 & 0.19 & 0.60 & $237 \pm 6$ & $0.359 \pm 0.01$ \\
2 & 0.60 & 0.19 & 0.19 & $456 \pm 25$ & $0.67 \pm 0.04$ \\
3 & 0.049 & 0.88 & 0.049 & $21 \pm 0.4$ & $0.311 \pm 0.02$ \\
4 & 0.33 & 0.60 & 0.049 & $296 \pm 6$ & $0.478 \pm 0.02$ \\
5 & 0.049 & 0.60 & 0.33 & $15.5 \pm 0.17$ & $0.249 \pm 0.015$ \\
6 & 0.60 & 0.33 & 0.049 & $470 \pm 15$ & $0.677 \pm 0.07$ \\
7 & 0.33 & 0.049 & 0.60 & $372 \pm 21$ & $0.562 \pm 0.06$ \\
8 & 0.88 & 0.049 & 0.049 & $536 \pm 28$ & $0.672 \pm 0.06$ \\
9 & 0.60 & 0.33 & 0.33 & $460 \pm 35$ & $0.736 \pm 0.07$ \\
10 & 0.049 & 0.049 & 0.60 & $47 \pm 0.5$ & $0.30 \pm 0.01$ \\
12 & 0.049 & 0.60 & 0.88 & $193 \pm 2$ & $0.258 \pm 0.01$ \\
13 & 0.19 & 0.33 & 0.19 & $99 \pm 11$ & $0.40 \pm 0.07$ \\
\hline
\end{tabular}

* Each formulation was loaded with $2 \%$ extract ( $0.02 \mathrm{~g}$ to obtain $1 \mathrm{~g}$ Fr-SNEDS). 
Model Statistical Analysis and ANOVA

The statistical analysis of simplex lattice design was performed by multiple linear regression analysis using the software. After statistical analysis for various models to determine the best fit model, DS and PDI were individually fitted to the quadratic model. Model signification and suitability were tested by analysis of variance (ANOVA) and the model statistics are illustrated in Table 4. ANOVA analysis showed significant $p$-values $(<0.0001)$ for both DS and PDI, and F-values of 127.14 and 39.64 for DS and PDI, respectively, that implied the model significance. For each response, the model was validated by the reasonable agreement of the predicted and the adjusted $R^{2}$ values (i.e., the difference is less than 0.2$)$. The actual model $\mathrm{R}^{2}$ and predicted and adjusted $\mathrm{R}^{2}$ values of the DS( $\left.\mathrm{Y}_{1}\right)$ were $0.9891,0.9813$, and 0.9684 , respectively. Considering PDI $\left(\mathrm{Y}_{2}\right)$, the actual model $\mathrm{R}^{2}$ and predicted and adjusted $\mathrm{R}^{2}$ values were of the PDI were $0.9659,0.9415$, and 0.8370 , respectively. Moreover, the adequate precision was higher than 4 (31.37 and 15.94 for DS and PDI, respectively), indicating an acceptable signal to noise ratio and consequently, the ability of the model to navigate the design space [40].

Table 4. ANOVA for dependent variables from simplex lattice design.

\begin{tabular}{|c|c|c|c|c|c|c|}
\hline & Source & $\begin{array}{l}\text { Sum of } \\
\text { Squares }\end{array}$ & df & $\begin{array}{l}\text { Mean } \\
\text { Square }\end{array}$ & F-Value & $p$-Value \\
\hline \multirow{6}{*}{ DS } & Model & $4.031 \times 10^{5}$ & 5 & 80620.85 & 127.14 & $<0.0001 *$ \\
\hline & Linear Mixture & $3.763 \times 10^{5}$ & 2 & $1.881 \times 10^{5}$ & 296.68 & $<0.0001$ * \\
\hline & $x_{1} x_{2}$ & $13,167.92$ & 1 & $13,167.92$ & 20.77 & $0.0026^{*}$ \\
\hline & $x_{1} x_{3}$ & 3790.31 & 1 & 3790.31 & 5.98 & 0.0444 * \\
\hline & $x_{2} x_{3}$ & 7353.97 & 1 & 7353.97 & 11.60 & 0.0114 * \\
\hline & \multicolumn{6}{|c|}{$\mathrm{R}^{2}=0.9891$, Prediction $\mathrm{R}^{2}=0.9813$, Adjusted $\mathrm{R}^{2}=0.9684$, Adeq. Precision $=31.3709$} \\
\hline \multirow{6}{*}{ PDI } & Model & 0.3678 & 5 & 0.0736 & 39.64 & $<0.0001 *$ \\
\hline & Linear Mixture & 0.3238 & 2 & 0.1619 & 87.26 & $<0.0001 *$ \\
\hline & $\mathrm{X}_{1} \mathrm{X}_{2}$ & 0.0101 & 1 & 0.0101 & 5.42 & 0.0528 \\
\hline & $x_{1} x_{3}$ & 0.0367 & 1 & 0.0367 & 19.79 & 0.0030 * \\
\hline & $x_{2} x_{3}$ & $8.837 \times 10^{-6}$ & 1 & $8.837 \times 10^{-6}$ & 0.0048 & 0.9469 \\
\hline & $\mathrm{R}^{2}=0.9659$ & diction $R^{2}=$ & & $\mathrm{d} \mathrm{R}^{2}=0.8370$ & leq. Prec & $=15.944$ \\
\hline
\end{tabular}

* Significant $(p<0.05)$.

The relation between dependent and independent variables was established using mathematical relationships. To study the effects, regression equations were generated for each response; the values of the coefficients of the independent variables (oil $\left(\mathrm{X}_{1}\right)$, surfactant $\left(X_{2}\right)$, and cosurfactant $\left(X_{3}\right)$ ) were reflecting the effects of these variables on each response. A positive coefficient represents a synergistic effect, whereas a negative coefficient indicates an opposite effect on the response; moreover, a greater coefficient indicates that the independent variable has a stronger effect on the response. Coefficients with more than one term indicate interaction; when two factors change simultaneously, a factor can produce a different degree of response [41].

\section{Effect of Formulation Composition on DS}

DS values of the prepared Fr-SNEDS formulations were found to be in the range of 15.5 to $536 \mathrm{~nm}$ (Table 3). The polynomial equation obtained for DS was:

$$
\text { DS }=+535.50 X_{1}-36.29 X_{2}+197.038 X_{3}+644.66 X_{1} X_{2}+345.86 X_{1} X_{3}-481.763 X_{2} X_{3}
$$

ANOVA analysis report for DS indicated that $\left(X_{1}\right),\left(X_{2}\right),\left(X_{1} X_{2}\right),\left(X_{1} X_{3}\right)$, and $\left(X_{2} X_{3}\right)$ are significant model terms $(p<0.05)$. As recorded in Table 4 , the oil $\left(X_{1}\right)$ and cosurfactant $\left(X_{3}\right)$ showed a positive effect on DS while surfactant $\left(X_{2}\right)$ had a negative effect. The interaction effects of $\left(X_{1} X_{2}\right)$ and $\left(X_{1} X_{3}\right)$ were positive, while the interaction effect of $\left(X_{2}\right.$ $X_{3}$ ) was negative (Figure $4 A-C$ ). 

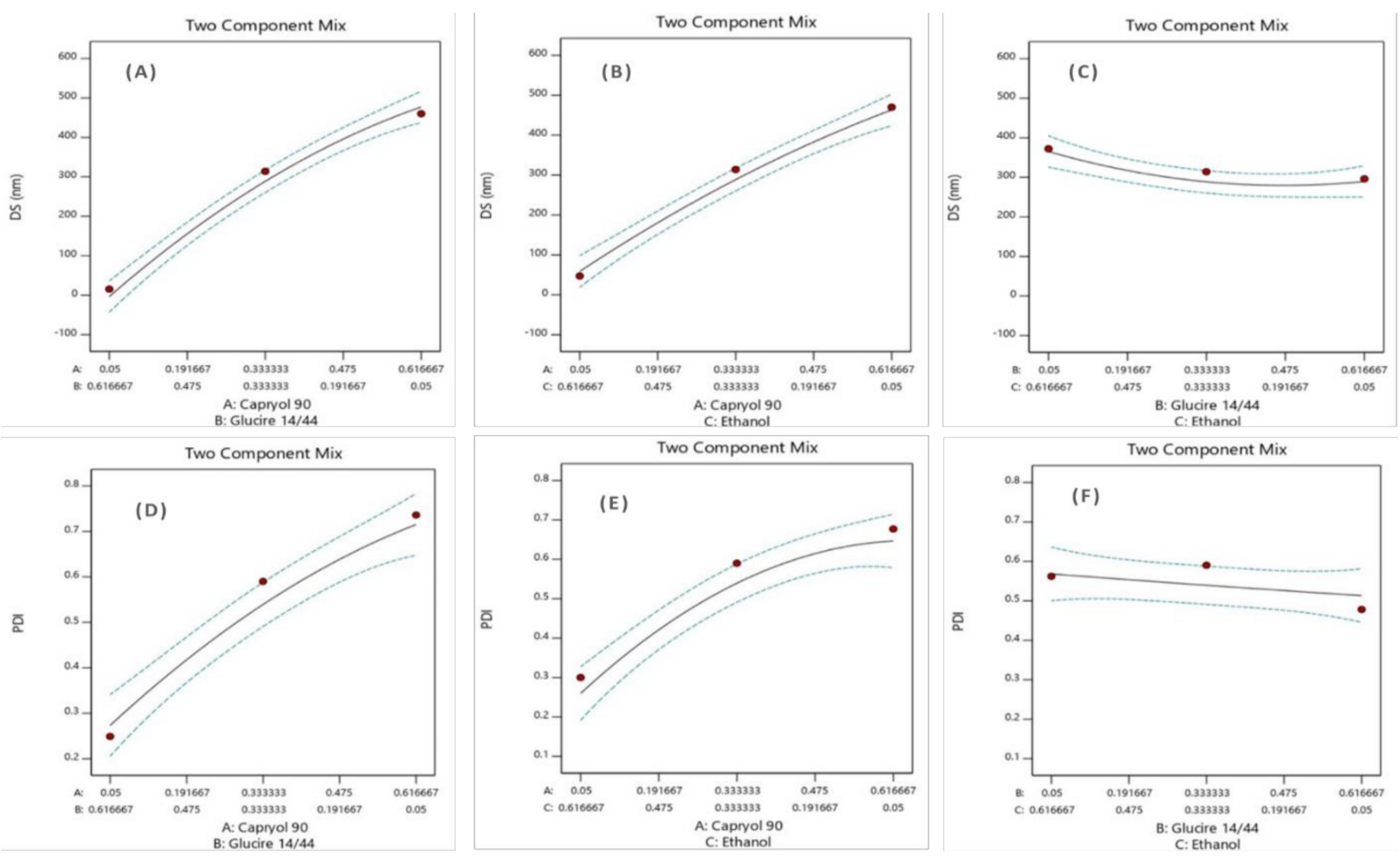

Figure 4. Factor effect plots showing the effect of two-component mix (Capryol $^{\mathrm{TM}}$ 90/Gelucire ${ }^{\circledR} 44 / 14, \mathrm{Capryol}^{\mathrm{TM}}$ 90/Ethanol, and Gelucire ${ }^{\circledR}$ 44/14/Ethanol): (A-C) on droplet size (DS) and (D-F) on poly dispersity index (PDI).

The effect of concentrations of oil, surfactant, and cosurfactant (independent variables) on DS is illustrated in Figure 5A,B, showing two- and three-dimensional contour and response surface plots. It was observed that the highest DS values are presented at the top of the figure (orange area) at increased Capryol ${ }^{\mathrm{TM}} 90$ percentage, while the lowest values (blue area) are found as the Gelucire ${ }^{\circledR} 44 / 14$ percentage increased. When the concentration of Gelucire ${ }^{\circledR} 44 / 14$ /ethanol mixture exceeded $75 \%$ of the system, DS values less than $200 \mathrm{~nm}$ are presented, indicating good emulsification efficiency.

\section{Effect of Formulation Composition on PDI}

The polydispersity index is an important parameter to evaluate the diameter distribution; lower PDI values indicate uniformity of droplet size within the formulation and assure its stability [42]. PDI values of the prepared Fr-SNEDS were found to be in the range of 0.249 to 0.736 . The obtained polynomial equation for PDI was:

$$
\mathrm{PDI}=+0.6605 \times{ }_{1}+0.2451 \mathrm{X}_{2}+0.171 \times{ }_{3}+0.563 \times{ }_{1} \mathrm{X}_{2}+1.076 \times{ }_{1} \mathrm{X}_{3}-0.0167 \times{ }_{2} \mathrm{X}_{3}
$$

ANOVA analysis report (Table 4$)$ indicated that $\left(X_{1}\right),\left(X_{2}\right),\left(X_{3}\right)$, and $\left(X_{1} X_{3}\right)$ are significant model terms $(p<0.05)$. Considering the above equation of PDI, the three factors $\left(X_{1}, X_{2}\right.$, and $\left.X_{3}\right)$ had a positive effect- the oil showed the highest positive value, followed by the surfactant, and the least value was recorded for the cosurfactant. The interaction effects of $\left(X_{1} X_{2}\right)$ and $\left(X_{1} X_{3}\right)$ were positive, while the interaction effect of $\left(X_{2} X_{3}\right)$ was negative (Figure $4 \mathrm{D}-\mathrm{F})$. 

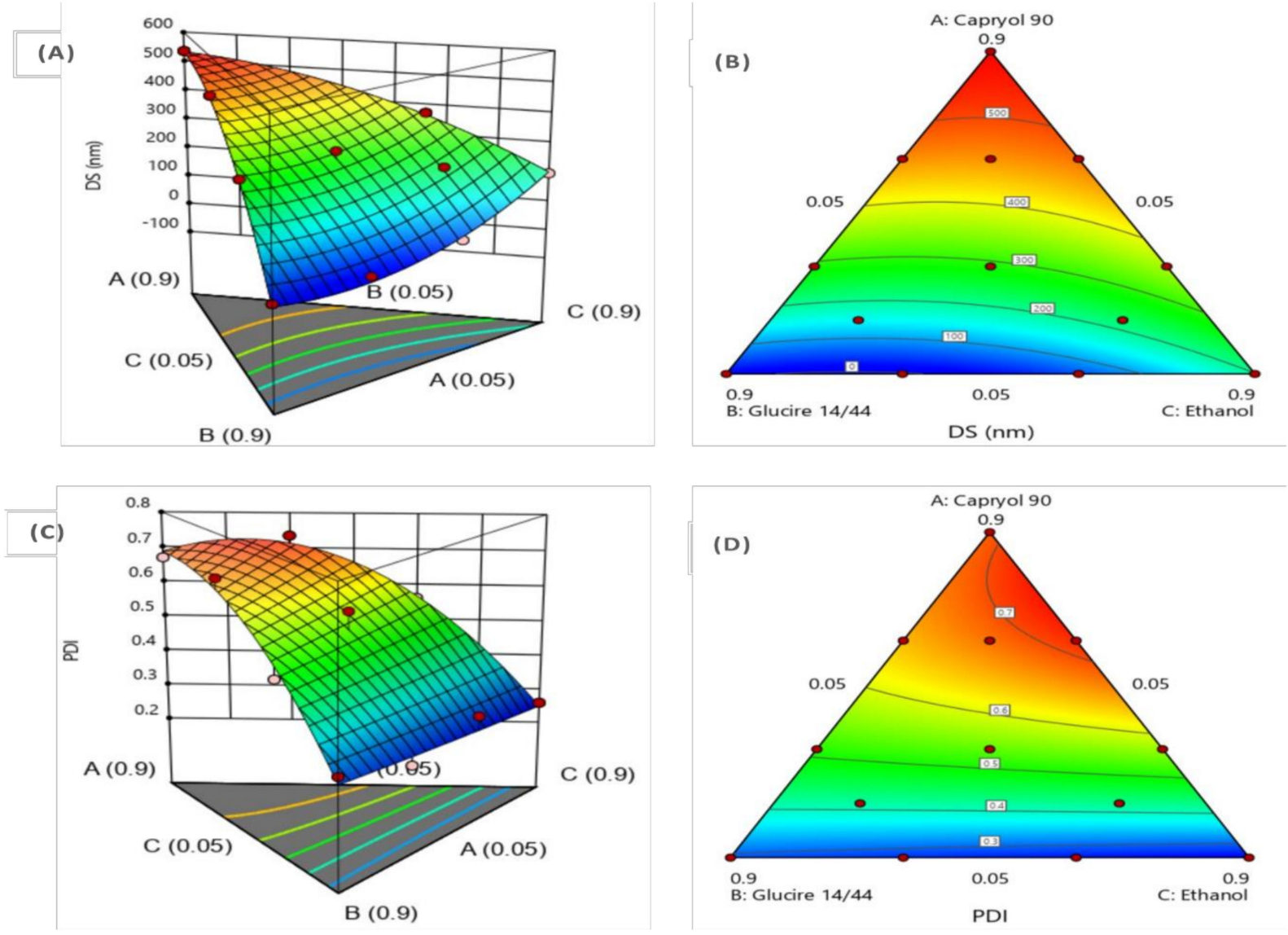

Figure 5. Response surface plots for the effect of Fr-SNEDS compositions (Capryol ${ }^{\mathrm{TM}}$ 90, Gelucire ${ }^{\circledR} 44 / 14$, and Ethanol): $(\mathbf{A}, \mathbf{B})$ on droplet size (DS) and (C,D) on poly dispersity index (PDI).

The effect of oil, surfactant, and cosurfactant on PDI is illustrated in Figure 5C,D, using two- and three-dimensional contour and response surface plots. PDI was significantly decreased by decreasing Capryol ${ }^{\mathrm{TM}} 90$ percentage, whereas Gelucire ${ }^{\circledR} 44 / 14$ and ethanol percentages were of low significance. An optimal range of the oil percentage for achieving a minimum PDI was around $5 \%$, with different percentages of surfactant and cosurfactant.

\section{Formulation Optimization}

The optimization process was performed using the desirability function to optimize DS and PDI to be minimized simultaneously. After applying the constraints cited in Table 5, the composition of the optimized Fr-SNEDS formulation was obtained with a desirability value of 0.964 , indicating that all goals are met perfectly. The composition of the optimized formulation was $5 \%, 48.7 \%$, and $46.3 \%$ for Capryol $^{\mathrm{TM}} 90$, Gelucire ${ }^{\circledR} 44 / 14$, and ethanol, respectively. The optimized formulation was prepared and evaluated for DS and PDI. The similarity between the predicted values (15.5 and 0.267 for DS and PDI, respectively) and the observed values (17.92 and 0.297 for DS and PDI, respectively) confirmed the validity of the generated mathematical equations and the used model. 
Table 5. Independent variables and respective limits for Fr-SNEDS formulations, model summary statistics of a quadratic model, constraints for optimization, factors levels for optimized Fr-SNEDS formulation, and their predicted and observed values.

\begin{tabular}{|c|c|c|c|c|}
\hline \multirow{2}{*}{\multicolumn{2}{|c|}{ Factors (Independent Variables) }} & \multicolumn{3}{|c|}{ Design Constraints } \\
\hline & & \multirow{2}{*}{$\frac{\text { Low Limit }(+\mathbf{0})}{0.05}$} & \multirow{2}{*}{$\frac{\text { Upper Limit } \mathbf{( + 1 )}}{0.9}$} & \multirow{2}{*}{$\frac{\text { Optimized Level }}{0.050}$} \\
\hline A: Capryol ${ }^{\mathrm{TM}} 90$ & & & & \\
\hline B: Gelucire ${ }^{\circledR} 44 / 14$ & & 0.05 & 0.9 & 0.487 \\
\hline C: Ethanol & & 0.05 & 0.9 & 0.463 \\
\hline $\begin{array}{c}\text { Responses } \\
\text { (Dependent Variables) }\end{array}$ & Constraints & $\begin{array}{c}\text { 95\% Prediction } \\
\text { Interval (Low/High) }\end{array}$ & Predicted & Observed \\
\hline DS (nm) & Minimize & $-39.08 / 70.08$ & 15.500 & $17.92 \pm 0.2$ \\
\hline PDI & Minimize & $0.173 / 0.36$ & 0.267 & $0.297 \pm 0.015$ \\
\hline
\end{tabular}

\subsection{Characterization of the Optimized Fr-SNEDS:}

3.3.1. Visual Inspection, DS, PDI, and ZP Measurements and Assessment of Self-Emulsification

Visual inspection of the optimized Fr-SNEDS showed clear, transparent, and homogeneous fluid with no signs of phase separation or precipitation. Fr-SNEDS showed a small size $(17.9 \pm 0.2 \mathrm{~nm})$ and a small value of PDI $(0.3 \pm 0.015)$, indicating a monodispersed population and a high uniformity among particles. Zp value was $-14.5 \pm 0.236 \mathrm{mV}$. The absolute $\mathrm{Zp}$ values $>8-9 \mathrm{mV}$ are essential for the system's stability. The emulsification time for the optimized Fr-SNEDS was less than one min and the \% transmittance of the formed dispersion was $97.8 \pm 0.2 \%$, which reflected good self-emulsification of the system.

\subsubsection{Thermodynamic Stability}

The optimized Fr-SNEDS showed good physical stability, as no changes in physical appearance, phase separation, or precipitation of the extract were observed.

\subsubsection{Surface Morphology by TEM}

The morphology of the formed dispersion globules of the optimized Fr-SNEDS is illustrated in the photograph of TEM (Figure 6A). The globules had a uniform spherical shape and a homogeneous size distribution. The diameters of the globules were in a range of 16-29 nm that was comparable with the DLS size results.
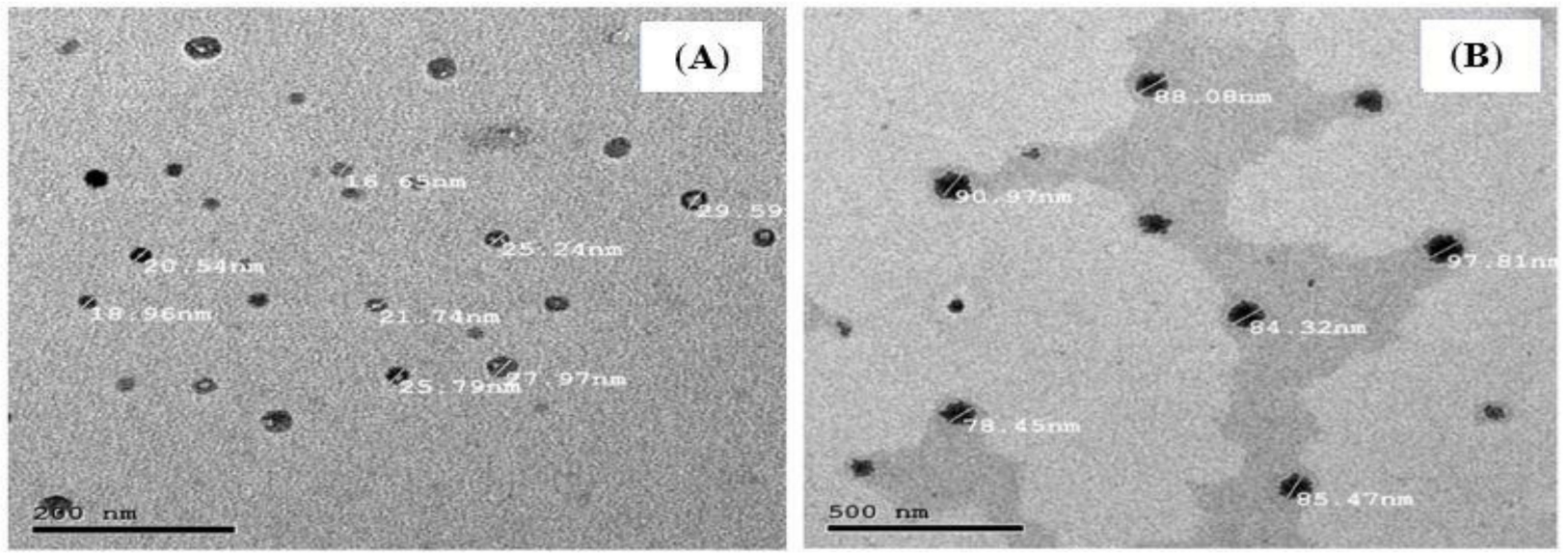

Figure 6. TEM photographs of Fr-SNEDS freshly prepared (A) and stored (B) formulation under ambient conditions for 12 months. 


\subsection{Assessment of Antimicrobial Activity}

The comparative assessment of the antimicrobial activity of Fr-extract and Fr-SNEDS revealed that both were potentially effective in suppressing microbial growth of all tested organisms with variable potencies (Table 6). The highest zone of inhibition was recorded against $H$. pylori and the lowest was against $M$. luteus. Fr-SNEDS exhibited higher zones of inhibition than the antimicrobial agents. Depending on the inhibition zone diameters, Fr-SNEDS showed a strong activity against all tested organisms (inhibition zone $>20 \mathrm{~mm}$ ), except M. luteus and C. albicans as it showed moderate (12 $\mathrm{mm}<$ inhibition zone $<20 \mathrm{~mm})$ activities [43], and no explanation is suggested. More expressive data on the antimicrobial properties were obtained through the determination of MIC and MBC values of Fr-extract and Fr-SNEDS (Figure 7). Fr-SNEDS exhibits lower MIC and MBC values compared with Fr-extract, where S. aureus and H. pylori were the most susceptible bacteria (MIC values of 5 and $25 \mu \mathrm{g} \mathrm{mL} \mathrm{m}^{-1}$, and $\mathrm{MBC}$ values of 5 and $100 \mu \mathrm{g} \mathrm{mL}^{-1}$ respectively), while M. luteus was the most resistant strain to Fr-SNEDS (MIC $=175 \mu \mathrm{g} \mathrm{mL}^{-1}$ ). In conclusion, the results showed a strong activity of Fr-SNEDS against S. aureus, S. epidermidis, B. subtilis, and a good activity against MRSA, which are conjugated organisms with lung cancer. In addition, there is a growing body of evidence supports an association between $H$. pylori infection with lung cancer [44,45].

Table 6. Zones of inhibition of Fr-extract, Fr-SNEDS, and plain SNEDS formulation against different bacterial strains compared with antimicrobial agents. Data are expressed as mean $\pm \mathrm{SD}(n=3)$.

\begin{tabular}{|c|c|c|c|c|c|c|c|}
\hline \multirow{2}{*}{$\begin{array}{c}\text { Microbial } \\
\text { Species }\end{array}$} & \multirow{2}{*}{ Fr-Extract } & \multirow{2}{*}{ Fr-SNEDS } & \multirow{2}{*}{$\begin{array}{c}\text { Plain } \\
\text { SNEDS }\end{array}$} & \multicolumn{4}{|c|}{ Antimicrobial Agents * } \\
\hline & & & & $\mathbf{F}$ & AMC & CFPM & VA \\
\hline S. aureus & $19 \pm 1.1$ & $23 \pm 1.3$ & $9 \pm 0.3$ & $20 \pm 1.3$ & $34 \pm 2.1$ & $25 \pm 1.9$ & $16 \pm 0.7$ \\
\hline S. epidermidis & $19 \pm 1.5$ & $24 \pm 1.5$ & $9 \pm 0.4$ & $19 \pm 0.9$ & NA & $20 \pm 1.7$ & $14 \pm 0.6$ \\
\hline B. subtilis & $22 \pm 0.2$ & $24 \pm 0.7$ & $9 \pm 0.3$ & $25 \pm 1.9$ & NA & $20 \pm 1.4$ & $17 \pm 0.5$ \\
\hline M. luteus & $20 \pm 0.5$ & $12 \pm 0.3$ & NA & $14 \pm 0.8$ & $18 \pm 0.3$ & $23 \pm 1.3$ & $15 \pm 0.8$ \\
\hline MRSA & $22 \pm 1.8$ & $22 \pm 1.4$ & $9 \pm 0.3$ & ND & ND & $\mathrm{R}$ & $17 \pm 0.9$ \\
\hline H. pylori ${ }^{* *}$ & $25 \pm 0.2$ & $28 \pm 1.1$ & $10 \pm 0.6$ & ND & ND & ND & NA \\
\hline C. albicans $* * *$ & $22 \pm 1.1$ & $14 \pm 1.0$ & NA & NA & NA & NA & NA \\
\hline
\end{tabular}

DMSO, Capryol ${ }^{\mathrm{TM}} 90$ and Gelucire ${ }^{\circledR} 44 / 14$ showed no zones of inhibitions. NA: Not active, ND: Not determined, R: Resistant. * Antimi-

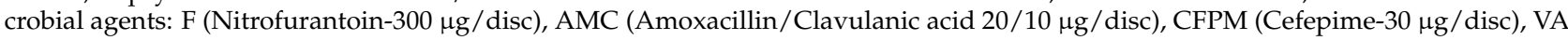
(vancomycin $30 \mu \mathrm{g} /$ disc). Fluconazole $(150 \mathrm{mg})$ and Metronidazole $\left(5 \mu \mathrm{g} /\right.$ disc) were induced zone of inhibition of 19 and $27 \mathrm{~mm}$ against ${ }^{* *}$ and ${ }^{* * *}$, respectively.

\subsection{Antiproliferative Study}

The antiproliferative testing was performed on lung cell line (A549) based on the antimicrobial findings, which showed good activity against the bacteria associated with lung cancer. Fr-SNEDS showed a significant antiproliferative effect when compared with Frextract ( $\mathrm{IC}_{50}$ : 20.49 and $109.5 \mu \mathrm{g} \mathrm{mL}{ }^{-1}$, respectively). It is obvious that the nano-dispersion enhanced the antiproliferative effect of Fr-extract. Additionally, the plain formulation exerted antiproliferative effects $\left(\mathrm{IC}_{50}: 78.61 \mu \mathrm{g} \mathrm{mL}^{-1}\right)$ when used in concentrations above $50 \mu \mathrm{g} \mathrm{mL}{ }^{-1}$. The cell viability was evaluated individually for each component in its respective concentration used in the formulation (Capryol ${ }^{\mathrm{TM}}$ 90, Gelucire ${ }^{\circledR} 44 / 14$, and ethanol) and no significant cell death was observed. 


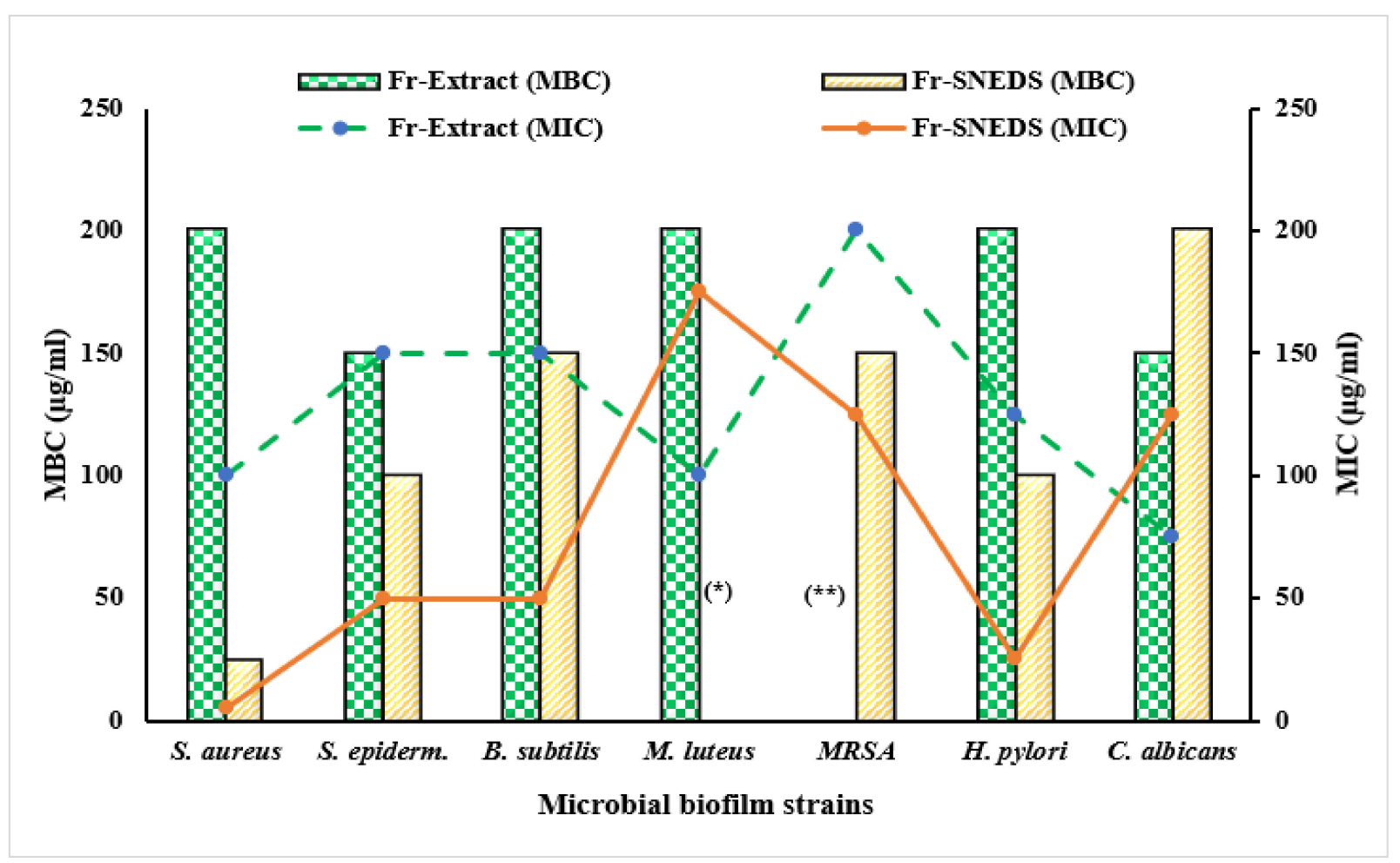

Figure 7. MICs and MBCs $\left(\mu \mathrm{g} \mathrm{mL} \mathrm{m}^{-1}\right)$ of Fr-extract and Fr-SNEDS formulation against different microbial strains. $\left({ }^{*}\right)$ FrSNEDS MBC against $M$. luteus was not determined, $\left({ }^{* *}\right)$ Fr-extract MBC against MRSA was $>200$.

\subsection{Stability Study}

The results of the stability study suggested a good physical stability of the optimized Fr-SNEDS. The formulation almost retained its properties-the stored formulation had DS close to the fresh one, PDI and ZP were slightly increased (Table 7). The self-emulsification parameters proved that the system dispersed within less than one min and the obtained dispersion was clear, with \% transmittance of 97.8\%. TEM photograph of the stored Fr-SNEDS showed homogeneously distributed spherical nano-sized globules (Figure 6B).

Table 7. The physicochemical parameters for fresh and stored Fr-SNEDS. Data are expressed as mean $\pm \operatorname{SD}(n=3)$.

\begin{tabular}{cccccc}
\hline \multirow{2}{*}{ Fr-SNEDS } & \multirow{2}{*}{ DS (nm) } & \multirow{2}{*}{ PDI } & \multirow{2}{*}{ ZP (mV) } & \multicolumn{2}{c}{ Assessment of Self-Emulsification } \\
\cline { 5 - 7 } & & & & Emulsification Time & \% Transmittance \\
\hline Freshly prepared & $17.9 \pm 0.2$ & $0.3 \pm 0.015$ & $-14.5 \pm 0.236$ & $<1$ min & $97.8 \pm 0.2$ \\
\hline Stored for one year & $22.3 \pm 0.7$ & $0.5 \pm 0.018$ & $-22.4 \pm 0.781$ & $<1 \mathrm{~min}$ & $98.1 \pm 0.1$ \\
\hline
\end{tabular}

\section{Discussion}

Despite the various therapeutic potentials of phytoconstituents, there are some limitations in their therapeutic applications due to low solubility, poor permeability, and difficulty of their formulation into suitable dosage forms. The use of nanotechnology in formulation could solve most of these encountered issues. In this work, we developed SNEDS formulation of a standardized Fr-extract; the physicochemical characters and stability of the optimized formulation were investigated. In addition, we compared the performance of Fr-SNEDS to the unformulated Fr-extract through in vitro screening of the antimicrobial and antiproliferative activities to investigate the influence of nano formulation and elucidate the possible potential therapeutic applications of this formulation. 
Frankincense is a natural resin with different therapeutic properties, including antimicrobial and cytotoxic activities, mainly due to its BA content. In this study, we determine the BA content in Fr-extract using HPLC. The HPLC analysis of the Fr-extract shows 44.96\% total content of Bas, where KBA has the major content, followed by AKBA and $\beta$-BA $(16.25 \%, 11.8 \%$, and $8.76 \%$, respectively). Our results agree with those reported, including that AKBA content of Boswellia species ranged from $0.05-5.40 \%$ [46]. In another report, AKBA content was estimated as $7.35 \%$ of gum resin $[30,47]$. Our findings indicated that the total content of the BAs is within $50 \%$, in agreement with previous works $[1,48]$.

Formulation development was a challenge due to the physical nature of the Fr-extract as it was a very sticky semisolid mass and insoluble in water. Excipients screening for development of Fr-SNEDS was based on the solubility study as loading of the poorly soluble Fr-extract will depend mainly on its solubility in different formulation components. Selection of the oily phase was based on Fr-extract solubility, while selection of surfactants and cosurfactants was based on both Fr-extract solubility and emulsification ability for the selected oil. Capryol ${ }^{\text {TM }} 90$, Gelucire ${ }^{\circledR} 44 / 14$ and ethanol were selected as oily phase, surfactant, and cosurfactant, respectively. Although the HLB values of the investigated surfactants were in the range of 14 to 16, there was a difference in their emulsification ability for Capryol ${ }^{\text {TM }}$ 90. It was reported that emulsification is influenced by HLB value, molecular structure, and chain length of the surfactant $[17,25]$. The cosurfactant further lowers the interfacial tension, improving the stability of the formed nanoemulsion dispersion. A simplex lattice design was used to investigate the effect of formulation variables on DS and PDI. Statistical analysis revealed that oil concentration had the most pronounced positive effect on both DS and PDI, i.e., they increased with increasing oil percentage. In addition, all interactions that involved oil concentration had a positive effect on DS and PDI. Conversely, surfactant concentration imparted a negative effect on DS. This effect has often been explained as being the result of increased surfactant adsorption around the oil-water interface of a droplet and the consequent decreased interfacial tension in the system. Surfactant molecules provide a mechanical barrier to coalescence, resulting in increased spontaneity of the nanoemulsion formation, which facilitates the formation of nanoemulsions with smaller droplets [17,49]. Ethanol as a cosurfactant can decrease interfacial tension between Capryol ${ }^{\mathrm{TM}} 90$ and water, adjust the flexibility of the interfacial membrane, and reduce the required amount of surfactant. The interaction between the surfactant and cosurfactant showed a negative effect on both responses. Consequently, the optimized Fr-SNEDS formulation generated based on the desirability function to obtain minimum DS and PDI was composed of the lowest oil concentration and almost equal surfactant and cosurfactant concentrations. Characterization of the optimized Fr-SNEDS showed good appearance, self-emulsification properties, and stability.

BAs and AKBA inhibit the growth of Gram-positive pathogens. AKBA effectively inhibits the $S$. aureus and S. epidermidis biofilms [6]. In our study, the antimicrobial assessment showed that Fr-SNEDS recorded wider zones of inhibition than Fr-extract for all tested organisms except $M$. luteus and $C$. albicans. It is worthy to mention that the plain SNEDS showed small zones of inhibition. The nanosized dispersions can penetrate the bacterial cell wall more efficiently and cause membrane disturbance and cell content disorganization. The smaller the DS is, the greater the extent of uptake through a barrier membrane, and this could explain the improved antimicrobial efficiency of Fr-SNEDS over Fr-extract [43,50-52]. Fr-SNEDS showed good activity against the bacteria associated with lung cancer. Based on these findings, the antiproliferative testing was performed on lung cell line and the results revealed a superior activity of the optimized Fr-SNEDS over the Fr-extract. Lee et al. [53] reported the enhanced effect of nanoemulsion formulation of tanshinone extract on the inhibition of lung cancer cells (A549); other authors reported the enhanced cytotoxic activity using SNEDS [22,54]. These results revealed that the developed Fr-SNEDS represented the extract in nanosized dispersions, which significantly improved the antimicrobial and antiproliferative activities of Fr-extract. 


\section{Conclusions}

Frankincense is widely used in pharmaceutical and nutraceutical preparations. Its bioactivity is based on the content of BAs, where KBA is a major compound. The optimized Fr-SNEDS enhanced the antimicrobial activity against the bacteria associated with lung diseases and improved the antiproliferative activity on human lung cell adenocarcinoma. Our findings suggested that the optimized Fr-SNEDS could be a potential adjuvant therapy for lung cancer. Further in vivo and clinical studies are required to investigate the therapeutic efficiency of such nano-formulations.

Author Contributions: S.S.E.-M. and O.S.E. perform the formulation, formula characterization, revised the manuscript, and designed the project. A.E.E.-H. performed the characterization of the extract, revised the manuscript, and conceived and designed the project. W.A.A. perform antimicrobial activity and drafted the manuscript. A.M.S. performed the extraction and drafted the manuscript. S.Z.E.-E. perform antiproliferative activity and drafted the manuscript. All authors have read and agreed to the published version of the manuscript.

Funding: This research received no external funding.

Institutional Review Board Statement: Not applicable.

Informed Consent Statement: Not applicable.

Data Availability Statement: All the data presented during this study are included in the article.

Conflicts of Interest: The authors confirm that this article content has no conflict of interest.

\section{References}

1. Mannino, G.; Occhipinti, A.; Maffei, M.E. Quantitative Determination of 3-O-Acetyl-11-Keto- $\beta$-Boswellic Acid (AKBA) and Other Boswellic Acids in Boswellia sacra Flueck (syn. B. carteri Birdw) and Boswellia serrata Roxb. Molecules 2016, 21, 1329. [CrossRef]

2. Chevrier, M.R.; Ryan, A.E.; Lee, D.Y.-W.; Zhongze, M.; Wu-Yan, Z.; Via, C.S. Boswellia carterii extract inhibits TH1 cytokines and promotes TH2 cytokines in vitro. Clin. Diagn. Lab. Immunol. 2005, 12, 575-580. [CrossRef]

3. Büchele, B.; Zugmaier, W.; Simmet, T. Analysis of pentacyclic triterpenic acids from frankincense gum resins and related phytopharmaceuticals by high-performance liquid chromatography. Identification of lupeolic acid, a novel pentacyclic triterpene. J. Chromatogr. B 2003, 791, 21-30. [CrossRef]

4. Frank, A.; Unger, M. Analysis of frankincense from various Boswellia species with inhibitory activity on human drug metabolising cytochrome P450 enzymes using liquid chromatography mass spectrometry after automated on-line extraction. J. Chromatogr. A 2006, 1112, 255-262. [CrossRef] [PubMed]

5. Schmiech, M.; Ulrich, J.; Lang, S.J.; Büchele, B.; Paetz, C.; St-Gelais, A.; Syrovets, T.; Simmet, T. 11-Keto- $\alpha$-Boswellic Acid, a Novel Triterpenoid from Boswellia spp. with Chemotaxonomic Potential and Antitumor Activity against Triple-Negative Breast Cancer Cells. Molecules 2021, 26, 366. [CrossRef]

6. Raja, A.F.; Ali, F.; Khan, I.A.; Shawl, A.S.; Arora, D.S.; Shah, B.A.; Taneja, S.C. Antistaphylococcal and biofilm inhibitory activities of acetyl-11-keto- $\beta$-boswellic acid from Boswellia serrata. BMC Microbiol. 2011, 11, 54. [CrossRef]

7. Alam, M.; Khan, H.; Samiullah, L.; Siddique, K.M. A review on phytochemical and pharmacological studies of Kundur (Boswellia serrata Roxb ex Colebr.)-A Unani drug. J. Appl. Pharm. Sci. 2012, 2, 148-156.

8. Xia, L.; Chen, D.; Han, R.; Fang, Q.; Waxman, S.; Jing, Y. Boswellic acid acetate induces apoptosis through caspase-mediated pathways in myeloid leukemia cells. Mol. Cancer Ther. 2005, 4, 381-388. [CrossRef]

9. Raja, A.F.; Ali, F.; Khan, I.A.; Shawl, A.S.; Arora, D.S. Acetyl-11-keto- $\beta$-boswellic acid (AKBA); targeting oral cavity pathogens. BMC Res. Notes 2011, 4, 406. [CrossRef]

10. Tambe, A.; Mokashi, P.; Pandita, N. Ex-vivo intestinal absorption study of boswellic acid, cyclodextrin complexes and poloxamer solid dispersions using everted gut sac technique. J. Pharm. Biomed. Anal. 2019, 167, 66-73. [CrossRef]

11. Kalhapure, R.S.; Suleman, N.; Mocktar, C.; Seedat, N.; Govender, T. Nanoengineered drug delivery systems for enhancing antibiotic therapy. J. Pharm. Sci. 2015, 104, 872-905. [CrossRef]

12. Donsì, F.; Annunziata, M.; Vincensi, M.; Ferrari, G. Design of nanoemulsion-based delivery systems of natural antimicrobials: Effect of the emulsifier. J. Biotechnol. 2012, 159, 342-350. [CrossRef]

13. El-Haddad, A.E.; Sheta, N.M.; Boshra, S.A. Isolation, Formulation, and Efficacy Enhancement of Morin Emulsified Carriers Against Lung Toxicity in Rats. AAPS PharmSciTech 2018, 19, 2346-2357. [CrossRef]

14. Pápay, Z.E.; Kállai-Szabó, N.; Ludányi, K.; Klebovich, I.; Antal, I. Development of oral site-specific pellets containing flavonoid extract with antioxidant activity. Eur. J. Pharm. Sci. 2016, 95, 161-169. [CrossRef] [PubMed] 
15. Grove, M.; Müllertz, A.; Nielsen, J.L.; Pedersen, G.P. Bioavailability of seocalcitol II: Development and characterisation of self-microemulsifying drug delivery systems (SMEDDS) for oral administration containing medium and long chain triglycerides. Eur. J. Pharm. Sci. 2006, 28, 233-242. [CrossRef]

16. Oh, D.H.; Kang, J.H.; Kim, D.W.; Lee, B.-J.; Kim, J.O.; Yong, C.S.; Choi, H.-G. Comparison of solid self-microemulsifying drug delivery system (solid SMEDDS) prepared with hydrophilic and hydrophobic solid carrier. Int. J. Pharm. 2011, 420, 412-418. [CrossRef] [PubMed]

17. Wang, L.; Dong, J.; Chen, J.; Eastoe, J.; Li, X. Design and optimization of a new self-nanoemulsifying drug delivery system. J. Colloid Interface Sci. 2009, 330, 443-448. [CrossRef] [PubMed]

18. Nazari-Vanani, R.; Moezi, L.; Heli, H. In vivo evaluation of a self-nanoemulsifying drug delivery system for curcumin. Biomed. Pharmacother. 2017, 88, 715-720. [CrossRef]

19. Hilbig, J.; Ma, Q.; Davidson, P.M.; Weiss, J.; Zhong, Q. Physical and antimicrobial properties of cinnamon bark oil conanoemulsified by lauric arginate and Tween 80. Int. J. Food Microbiol. 2016, 233, 52-59. [CrossRef] [PubMed]

20. Alwadei, M.; Kazi, M.; Alanazi, F.K. Novel oral dosage regimen based on self-nanoemulsifying drug delivery systems for codelivery of phytochemicals—Curcumin and thymoquinone. Saudi Pharm. J. 2019, 27, 866-876. [CrossRef] [PubMed]

21. Aldawsari, H.M.; Elfaky, M.A.; Fahmy, U.A.; Aljaeid, B.M.; Alshareef, O.A.; El-Say, K.M. Development of a fluvastatin-loaded self-nanoemulsifying system to maximize therapeutic efficacy in human colorectal carcinoma cells. J. Drug Deliv. Sci. Technol. 2018, 46, 7-13. [CrossRef]

22. Batool, A.; Arshad, R.; Razzaq, S.; Nousheen, K.; Kiani, M.H.; Shahnaz, G. Formulation and evaluation of hyaluronic acid-based mucoadhesive self nanoemulsifying drug delivery system (SNEDDS) of tamoxifen for targeting breast cancer. Int. J. Biol. Macromol. 2020, 152, 503-515. [CrossRef] [PubMed]

23. Li, Y.; McClements, D.J. Inhibition of lipase-catalyzed hydrolysis of emulsified triglyceride oils by low-molecular weight surfactants under simulated gastrointestinal conditions. Eur. J. Pharm. Biopharm. 2011, 79, 423-431. [CrossRef]

24. Nazari-Vanani, R.; Azarpira, N.; Heli, H. Development of self-nanoemulsifying drug delivery systems for oil extracts of Citrus aurantium L. blossoms and Rose damascena and evaluation of anticancer properties. J. Drug Deliv. Sci. Technol. 2018, 47, 330-336. [CrossRef]

25. Sanka, K.; Suda, D.; Bakshi, V. Optimization of solid-self nanoemulsifying drug delivery system for solubility and release profile of clonazepam using simplex lattice design. J. Drug Deliv. Sci. Technol. 2016, 33, 114-124. [CrossRef]

26. Tang, B.; Cheng, G.; Gu, J.-C.; Xu, C.-H. Development of solid self-emulsifying drug delivery systems: Preparation techniques and dosage forms. Drug Discov. Today 2008, 13, 606-612. [CrossRef]

27. Cui, J.; Yu, B.; Zhao, Y.; Zhu, W.; Li, H.; Lou, H.; Zhai, G. Enhancement of oral absorption of curcumin by self-microemulsifying drug delivery systems. Int. J. Pharm. 2009, 371, 148-155. [CrossRef] [PubMed]

28. Sachan, A.K.; Gupta, A. A Review on Nanotized Herbal Drugs. Int. J. Pharm. Sci. Res. 2015, 6, 961-970. [CrossRef]

29. El-Haddad, A.E.; Saadeldeen, A.M.; El-Emam, S.Z. Anti-angiogenic Activity of Major Phenolics in Tamarind Assessed with Molecular Docking Study on VEGF Kinase Proteins. Pak. J. Biol. Sci. 2019, 22, 502-509. [CrossRef]

30. Mostafa, D.M.; Ammar, N.M.; El-Alim, S.H.A.; Kassem, A.A.; Hussein, R.A.; Awad, G.; El-Awdan, S.A.-W. Boswellia carterii liquisolid systems with promoted anti-inflammatory activity. Curr. Drug Deliv. 2015, 12, 454-463. [CrossRef]

31. ICH Q8 International Conference on Harmonization (ICH) of Technical Requirements for Registration of Pharmaceuticals for Human Use 2005. Available online: https:/ / www.ncbi.nlm.nih.gov/pmc/articles/PMC4544148/ (accessed on 3 June 2021).

32. Nornoo, A.O.; Osborne, D.W.; Chow, D.S.-L. Cremophor-free intravenous microemulsions for paclitaxel I: Formulation, cytotoxicity and hemolysis. Int. J. Pharm. 2008, 349, 108-116. [CrossRef]

33. Ujilestari, T.; Martien, R.; Ariyadi, B.; Dono, N.D. Self-nanoemulsifying drug delivery system (SNEDDS) of Amomum compactum essential oil: Design, formulation, and characterization. J. Appl. Pharm. Sci. 2018, 8, 14-21. [CrossRef]

34. Cuiné, J.F.; Charman, W.N.; Pouton, C.W.; Edwards, G.A.; Porter, C.J.H. Increasing the proportional content of surfactant (Cremophor EL) relative to lipid in self-emulsifying lipid-based formulations of danazol reduces oral bioavailability in beagle dogs. Pharm. Res. 2007, 24, 748-757. [CrossRef]

35. Gupta, S.; Chavhan, S.; Sawant, K.K. Self-nanoemulsifying drug delivery system for adefovir dipivoxil: Design, characterization, in vitro and ex vivo evaluation. Colloids Surf. A Physicochem. Eng. Asp. 2011, 392, 145-155. [CrossRef]

36. Tawfick, M.M.; Alshareef, W.A.; Bendary, H.A.; Elmahalawy, H.; Abdulall, A.K. The emergence of carbapenemase bla $a_{\mathrm{NDM}}$ genotype among carbapenem-resistant Enterobacteriaceae isolates from Egyptian cancer patients. Eur. J. Clin. Microbiol. Infect. Dis. 2020, 39, 1251-1259. [CrossRef] [PubMed]

37. Dolinsky, A.L.; Ohiro, R.K.; Fan, W.; Xiao, C.; Wu, F. National Committee for Clinical Laboratory Standards. 2000. Performance standard for antimicrobial susceptibility testing. Document M100-S10. J. Int. Med. Res. 2017, 46, 18. [CrossRef]

38. Nazeam, J.A.; AL-Shareef, W.A.; Helmy, M.W.; El-Haddad, A.E. Bioassay-guided isolation of potential bioactive constituents from pomegranate agrifood by-product. Food Chem. 2020, 326, 126993. [CrossRef] [PubMed]

39. Mosmann, T. Rapid colorimetric assay for cellular growth and survival: Application to proliferation and cytotoxicity assays. $J$. Immunol. Methods 1983, 65, 55-63. [CrossRef]

40. Elzahraa, F.; Elsayed, I.; Kamal, M.; Hassen, A.; Ibrahim, M. Response surface optimization, Ex vivo and In vivo investigation of nasal spanlastics for bioavailability enhancement and brain targeting of risperidone. Int. J. Pharm. 2017, 530, 1-11. [CrossRef] 
41. Thapa, P.; Hyung, D.; Soo, M.; Hoon, S. Effects of granulation process variables on the physical properties of dosage forms by combination of experimental design and principal component analysis. Asian J. Pharm. Sci. 2019, 14, 287-304. [CrossRef] [PubMed]

42. Khattab, A.; Hassanin, L.; Zaki, N. Self-nanoemulsifying drug delivery system of coenzyme (Q10) with improved dissolution, bioavailability, and protective efficiency on liver fibrosis. AAPS PharmSciTech 2017, 18, 1657-1672. [CrossRef] [PubMed]

43. Rota, M.C.; Herrera, A.; Martínez, R.M.; Sotomayor, J.A.; Jordán, M.J. Antimicrobial activity and chemical composition of Thymus vulgaris, Thymus zygis and Thymus hyemalis essential oils. Food Control 2008, 19, 681-687. [CrossRef]

44. Mounika, P. Helicobacter pylori Infection and Risk of Lung Cancer: A Meta-Analysis. Lung Cancer Int. 2013, 2013, 1-6. [CrossRef] [PubMed]

45. González, I.; Araya, P.; Roj, A. Helicobacter pylori infection and lung cancer: New insights and future challenges. Chin. J. Lung Cancer 2018, 21, 658-662. [CrossRef]

46. Ganzera, M.; Khan, I.A. A reversed phase high performance liquid chromatography method for the analysis of boswellic acids in Boswellia serrata. Planta Med. 2001, 67, 778-780. [CrossRef]

47. Singh, S.; Khajuria, A.; Taneja, S.C.; Johri, R.K.; Singh, J.; Qazi, G.N. Boswellic acids: A leukotriene inhibitor also effective through topical application in inflammatory disorders. Phytomedicine 2008, 15, 400-407. [CrossRef]

48. Büchele, B.; Zugmaier, W.; Genze, F.; Simmet, T. High-performance liquid chromatographic determination of acetyl-11-keto- $\alpha-$ boswellic acid, a novel pentacyclic triterpenoid, in plasma using a fluorinated stationary phase and photodiode array detection: Application in pharmacokinetic studies. J. Chromatogr. B 2005, 829, 144-148. [CrossRef]

49. Taha, E.; Samy, A.; Kassem, A.; Khan, M. Response Surface Methodology for the Development of Self-Nanoemulsified Drug Delivery System (SNEDDS) of All-Trans-Retinol Acetate. Pharm. Dev. Technol. 2005, 10, 363-370. [CrossRef] [PubMed]

50. Bakr, R.O.; Tawfike, A.; El-Gizawy, H.A.; Tawfik, N.; Abdelmohsen, U.R.; Abdelwahab, M.F.; Alshareef, W.A.; Fayez, S.M.; El-Mancy, S.M.S.; El-Fishawy, A.M.; et al. The metabolomic analysis of five Mentha species: Cytotoxicity, anti-Helicobacter assessment, and the development of polymeric micelles for enhancing the anti-Helicobacter activity. RSC Adv. 2021, 11, 7318-7330. [CrossRef]

51. Ahmed, I.S.; Elnahas, O.S.; Assar, N.H.; Gad, A.M.; Hosary, R. Nanocrystals of fusidic acid for dual enhancement of dermal delivery and antibacterial activity: In vitro, ex vivo and in vivo evaluation. Pharmaceutics 2020, 12, 199. [CrossRef]

52. Zhang, H.; Cui, Y.; Zhu, S.; Feng, F.; Zheng, X. Characterization and antimicrobial activity of a pharmaceutical microemulsion. Int. J. Pharm. 2010, 395, 154-160. [CrossRef] [PubMed]

53. Lee, W.D.; Liang, Y.J.; Chen, B.H. Effects of tanshinone nanoemulsion and extract on inhibition of lung cancer cells A549. Nanotechnology 2016, 27, 495101. [CrossRef] [PubMed]

54. Usmani, A.; Mishra, A.; Arshad, M.; Jafri, A. Development and evaluation of doxorubicin self nanoemulsifying drug delivery system with Nigella Sativa oil against human hepatocellular carcinoma. Artif. Cells Nanomed. Biotechnol. 2019, 47, 933-944. [CrossRef] [PubMed] 